\title{
Influence of hydrothermal ageing on the residual stresses and mechanical behavior of carbon/epoxy composite laminates
}

\author{
WEN Zhongmeng ${ }^{1, a^{*}}$, GONG XiaoLu ${ }^{1, b}$ \\ ${ }^{1}$ Laboratory of Mechanical systems and Concurrent Engineering (LASMIS) \\ University of Technology of Troyes (UTT), 12 Rue Marie Curie, 10004 Troyes, \\ azhongmeng.wen@utt.fr, bong@utt.fr
}

\begin{abstract}
Keywords: residual stresses; composite laminate; incremental hole-drilling method; mechanical properties; aging effects

Abstract. In this work, the residual stresses for composite laminates $\left[0_{2} / \theta_{2}\right]_{S}$ are determined by means of the incremental hole-drilling method with a formula to express the relation between the residual stresses and the relaxed strains around the drilled hole. Then the ageing tests related to hydrothermal condition are carried out to analyze the influence on the residual stresses redistributions and also on the mechanical behaviors of the carbon/epoxy laminates.
\end{abstract}

\section{Introduction}

Carbon/epoxy composite materials are widely used in civil engineering applications [1] considering their specific advantages such as, high stiffness, high strength, corrosion resistance, inherent damping properties and low coefficient of thermal expansion, etc. However, generally, in the manufacturing process of composite laminates using epoxy resin impregnated carbon fiber, residual stresses are formed due to polymer shrinkages and mismatches of thermal coefficients between fiber and matrix, also between the plies with different orientations [2]. The thermal residual stresses during fabrication affect the composites mechanical performances, for example, damage, failure and service life [3]; besides, during service life of composite structures, the kinetic heating in humid condition results in swelling stresses in laminates. These stresses may initially counteract the curing stress thereby resulting in the variation of composites mechanical properties[4].

The present work aims to investigate the residual stresses in composite laminates and study the hydrothermal effects on the internal stresses redistribution and also on the composites mechanical properties. This paper consists of two main parts. At first, the incremental hole-drilling method is used to uncover the residual stresses in composite laminates $\left[0_{2} / \theta_{2}\right]_{\mathrm{s}}$. In this process, a theoretical formula is deduced to express the relation between the relaxed strains on the laminates surface and the residual stresses in laminates. The finite element method is employed to determine the calibration coefficients within the formula. Then, the accelerated aging tests related to hydrothermal condition are realized to analyze their effect on the residual stresses redistribution and the mechanical properties of the composite laminates $\left[0_{2} / \theta_{2}\right]_{\mathrm{s}}$.

\section{Residual stresses determination}

In most cases, experimental determination of the residual stresses can be separated into two steps [5]: i) Measurement of residual strains caused by deliberately removing material to allow the stresses to relax through strain gages, interferometry, X-ray diffraction or other techniques; ii) the general relation between the residual stresses and strains relaxed on specimen surface is applied to calculate the residual stresses in materials. In the case of composite laminates $\left[0_{2} / \theta_{2}\right]_{\mathrm{s}}$, the facts that non-uniform distribution of residual stresses in through-depth and the anisotropic property of composite laminates should be admitted. In order to determine the residual strain profile in hole-depth direction, the incremental hole-drilling method [6] is applied. Considering the anisotropy of the laminates $\left[0_{2} / \theta_{2}\right]_{\mathrm{s}}$, a general formula is deduced to express the stress-strain relation. 
Theory procedure. The proposed stress-strain formula is based on the following hypothesizes. The residual stress state in composite laminates is regarded as in-plane stress state. The stress in through-thickness direction is much smaller than those in other two directions and can be neglected; the strain in composite laminate is linear elastic. Supposing the residual stress state in materials is expressed in an arbitrary coordinate $(o, x, y) ; \sigma_{x}, \sigma_{y}, \tau_{x y}$ and $\tau_{y x}$ represent the stress components with $\tau_{y x}=\tau_{x y}$. Based on the previous work [7], a formula (Eq. 1) is deduced to express the stress-strain relation in composite laminate. In the formula, three calibration coefficients $\mathrm{A}, \mathrm{B}$ and $\mathrm{C}$ are

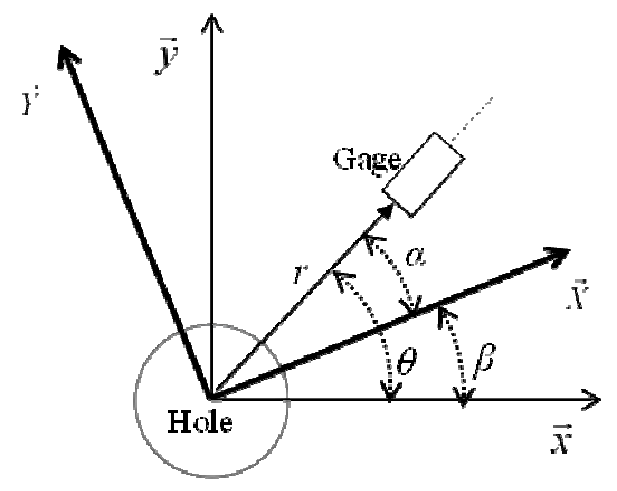

Fig. 1 Coordinate system for stress-strain model introduce to cover the stress concentration effects because of the drilled hole, besides the intrinsic material properties (such as Young's modulus, Poisson's ratio).

$$
\varepsilon_{r}=A X+B Y \cos [2(\theta-\beta)]+C Y \sin [2(\beta-\theta)]
$$

where $X=\sigma_{X}+\sigma_{Y}, Y=\sigma_{X}-\sigma_{Y} ; \sigma_{X}, \sigma_{Y}$ and $\beta$ represent two principle stresses and principle direction, respectively; $\theta$ corresponds the stain gage position; $\varepsilon_{r}$ is the strain measured in the gage direction; as illustrated in Fig.1. Moving to the incremental hole-drilling method, this stress-strain relation can be deduced with the incremental drilling characteristics as:

$$
\varepsilon_{i n}=A_{i n}\left(\sigma_{X h i}+\sigma_{Y h i}\right)+B_{i n}\left(\sigma_{X h i}-\sigma_{Y h i}\right) \cos \left[2\left(\theta-\beta_{i}\right)\right]+C_{i n}\left(\sigma_{X h i}-\sigma_{Y h i}\right) \sin \left[2\left(\beta_{i}-\theta\right)\right]
$$

where the radial strain $\varepsilon_{\text {in }}$ represents the effect of residual stresses within $\mathrm{i}^{\text {th }}$ increment when the hole is drilled into the $\mathrm{n}^{\text {th }}$ increment with a total depth of $h_{n} ; \sigma_{X h i}, \sigma_{Y h i}$ are the principal stresses within $\mathrm{i}^{\text {th }}$ increment and $\beta_{i}$ reveals the principal direction.

$A_{i n}, B_{i n}$ and $C_{\text {in }}$ are the calibration coefficients related to the $\mathrm{i}^{\text {th }}$ increment within a hole drilled up to $\mathrm{n}$ increments. The finite element method is used to determine these calibration coefficients. The main principle of calibration is to apply a stress state equivalent to the released stress within an increment during the drilling process, and then the stress state in composite laminates would stay in its
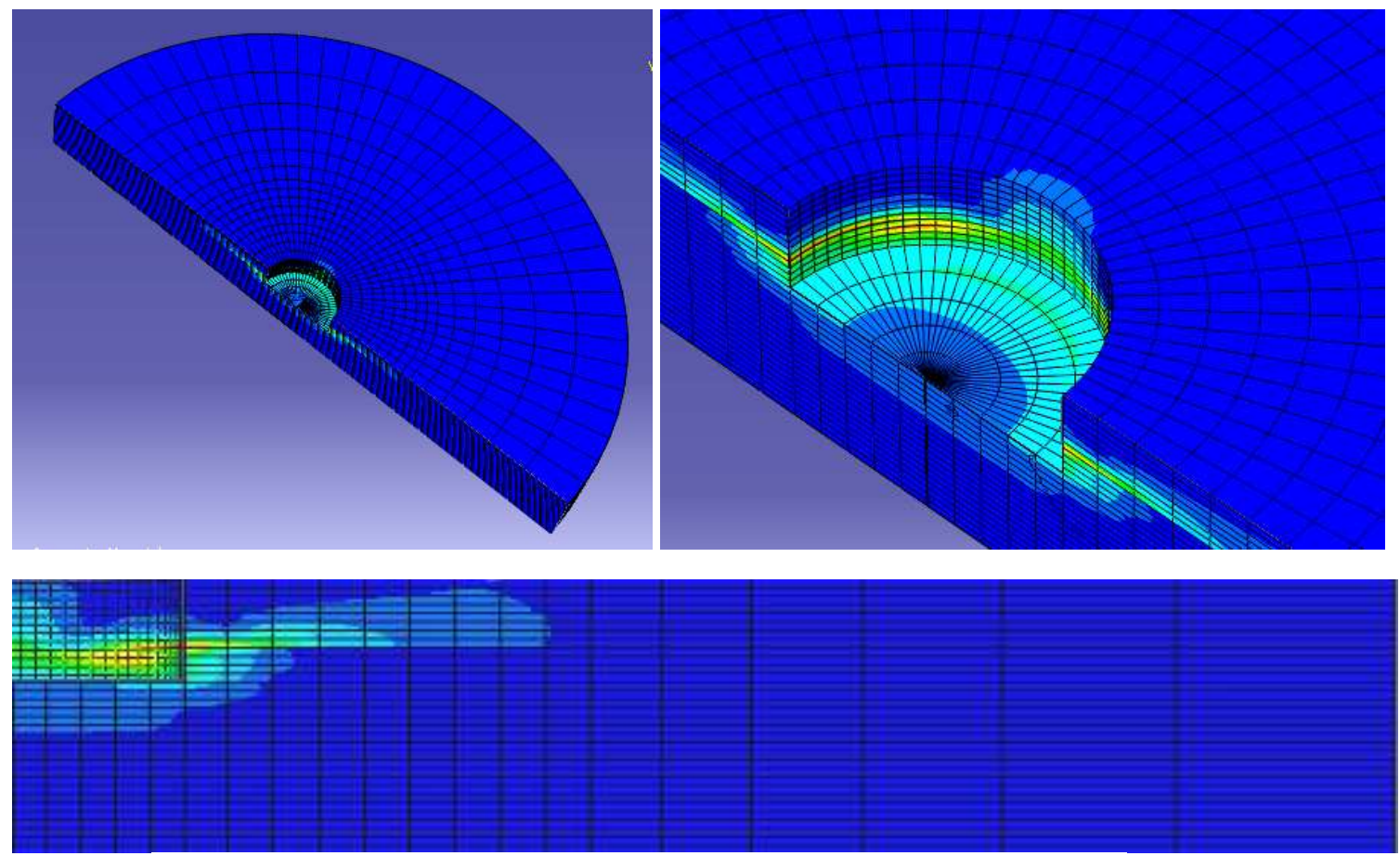

Fig. 2 Numerical modeling for calibration coefficient determinations 
equilibrium [6,8]. A three-dimensional finite element model (Fig. 2)was performed by using ABAQUS/Standard with elements C3D8 and elements C3D6. During the calibration process, the radial stress $\sigma_{\mathrm{r}}$ and the shear stress $\sigma_{\mathrm{r} \theta}$ between the removed layers and the main part were applied in the model. To calculate the coefficients $A_{i n}$, an equibiaxial in-plane residual stress state within the $i^{\text {th }}$ increment was applied in the model: $\sigma_{\mathrm{r}}=\sigma_{\theta}=\sigma, \tau=0$. Similarly, $\mathrm{B}_{\text {in }}$ and $\mathrm{C}_{\mathrm{in}}$ could be determined by superimposing the pure shear residual stress state, which was equivalent to a harmonic distribution of the radial stress along the hole boundary $\sigma_{r}=-\sigma \cos (2 \theta)$ combined with a shearing stress $\tau_{\mathrm{r} \theta}=\sigma \sin (2 \theta)$, both acting on the $i^{\text {th }}$ increment lateral face. Therefore, all the required calibration coefficients were determined.

In order to determine the strains because of the released residual stresses within the $\mathrm{n}^{\text {th }}$ increment [8], the superposition expression $\left(\varepsilon_{n n}=\varepsilon_{n}-\sum_{i=1}^{n-1} \varepsilon_{i n}\right.$ ) was employed. If a strain gage rosette is pasted on specimen with the positions $\theta^{1}=0^{\circ}, \theta^{2}=-135^{\circ}, \theta^{3}=90^{\circ}$, three equations adapted from Eq. 2 can be obtained and the residual stresses within the $n^{\text {th }}$ increment can be calculated, as the solutions of these equations:

$$
\left\{\begin{array}{c}
\sigma_{X h n}=\frac{\left(C_{n n} \cos 2 \beta_{n}-B_{n n} \sin 2 \beta_{n}+A_{n n}\right) \varepsilon_{n n}^{1}+\left(B_{n n} \cos 2 \beta_{n}+C_{n n} \sin 2 \beta_{n}-A_{n n}\right) \varepsilon_{n n}^{2}}{2 A_{n n}\left[B_{n n}\left(\cos 2 \beta_{n}-\sin 2 \beta_{n}\right)+C_{n n}\left(\sin 2 \beta_{n}+\cos 2 \beta_{n}\right)\right]} \\
\sigma_{Y h n}=\frac{\left(C_{n n} \cos 2 \beta_{n}-B_{n n} \sin 2 \beta_{n}-A_{n n}\right) \varepsilon_{n n}^{1}+\left(B_{n n} \cos 2 \beta_{n}+C_{n n} \sin 2 \beta_{n}+A_{n n}\right) \varepsilon_{n n}^{2}}{2 A_{n n}\left[B_{n n}\left(\cos 2 \beta_{n}-\sin 2 \beta_{n}\right)+C_{n n}\left(\sin 2 \beta_{n}+\cos 2 \beta_{n}\right)\right]} \\
\beta_{n}=1 / 2 \operatorname{ar} \tan \left(-\frac{B_{n n}\left(2 \varepsilon_{n n}^{2}-\varepsilon_{n n}^{1}-\varepsilon_{n n}^{3}\right)-C_{n n}\left(\varepsilon_{n n}^{3}-\varepsilon_{n n}^{1}\right)}{C_{n n}\left(2 \varepsilon_{n n}^{2}-\varepsilon_{n n}^{1}-\varepsilon_{n n}^{3}\right)+B_{n n}\left(\varepsilon_{n n}^{3}-\varepsilon_{n n}^{1}\right)}\right)
\end{array}\right.
$$

Experimental procedure. Carbon/epoxy composite laminates were manufactured with prepreg unidirectional plies (type of epoxy is HexPly® M10, $\mathrm{V}_{\mathrm{f}}=55 \%$, nominal cured ply thickness $=0.2 \mathrm{~mm}$ ) by hand lay-up. The cure process was based on the nominal cure cycle $\left(120^{\circ} \mathrm{C}\right.$ for $\left.1 \mathrm{~h}\right)$ for epoxy resin HexPly ${ }^{\circledR}$ M10 provided by the supplier with air cooling condition. Five different types of laminates, as $\left[0_{2} / \theta_{2}\right]_{\mathrm{s}}\left(\theta=0^{\circ}, 30^{\circ}, 45^{\circ}, 60^{\circ}, 90^{\circ}\right)$ were employed for residual stresses determination in this work (Fig. 3 ).

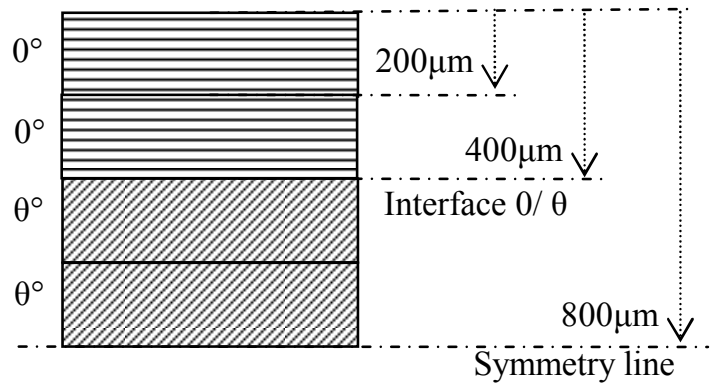

Fig. 3 Dimensions of the laminate $\left[0_{2} / \theta_{2}\right]_{\mathrm{s}}$

Drillings were conducted using 2 flute square end mill. After each increment, the cutter was withdrawn from the hole and the strain measured by using a computerized data acquisition system. In order to measure the strains around the drilled hole, a 3-element strain gage rosette was pasted on the specimen with gage 1 aligned with the fiber longitudinal direction. Alignment of gage with the desired direction should be respected. For the hole-drilling method, firstly, quality of the drilled hole should be guaranteed, such as cylindricity and surface finish; secondly, drilling procedure should not introduce the distinct damage around the hole, for example surface scaling and delamination cracks along the ply interface. According to the previous contribution [9] and experimental results comparison, drilling parameters were chosen as follows: the drill bit diameter $2 \mathrm{~mm}$; the translational speed $10 \mu \mathrm{m} / \mathrm{s}$ and the spindle speed of drill bit $5000 \mathrm{r} / \mathrm{min}$. After the drilling, optical microscope was used to verify the quality of hole, showing no significant damage around the hole and without cracking on the lateral face.

According to the related literature [8,9], the results accuracy is related to incremental number. The experiments for two increments per ply $(100 \mu \mathrm{m} /$ increment $)$ were carried out in this work. Knowing the ply thickness is $200 \mu \mathrm{m}$, the interface of plies in different orientations should be in depth of 400 $\mu \mathrm{m}$ for laminates $\left[0_{2} / \theta_{2}\right]_{\mathrm{s}}$. In order to verify the precise position between adjacent plies, the specimen sections were observed using optical microscope and the real position was located at the depth of 400 
$\pm 10 \mu \mathrm{m}$. During the experiments, the hole was drilled with 8 increments up to a depth of $800 \mu \mathrm{m}$, which corresponded to the depth of fourth plies, half-thickness of the specimens.

Residual stresses in laminates $\left[\mathbf{0}_{2} / \boldsymbol{\theta}_{2}\right]_{\mathrm{S}}$. With the proposed formula and the experimental residual strains results, the residual stresses for different laminates can be obtained, as illustrate in Fig. 4. Considering the symmetric structure of each laminate, the residual stress distributions should be symmetric in through-thickness direction and thus, the distribution profiles are only presented up to the half thickness of the laminates.

From the results for each laminate, it is distinct that the residual stresses within the plies in same orientation are almost uniform. Considering the classic laminate theory for residual stress calculation, the results are plotted as stage for each increment. Different symbols in Fig. 4 represent various laminate types: $\left[0_{2} / \theta_{2}\right]_{\mathrm{s}}\left(\theta=0^{\circ}, 30^{\circ}, 45^{\circ}, 60^{\circ}, 90^{\circ}\right)$. For the first two plies in direction $0^{\circ}$ (depth less than $400 \mu \mathrm{m}$ ) and the two central plies with orientation $\theta^{\circ}$, this tendency is conspicuous; however, the residual stress values for the latter are totally different from those in the first two plies.

In the case of cross-ply laminates $\left[0_{2} / 90_{2}\right]_{\mathrm{s}}$, the residual stresses are the most important compared with other types of laminates, which indicates that the main residual stresses come from the difference between ply orientations. Within the plies $0^{\circ}$, the two principal stresses are equal to $-45 \mathrm{MPa}$ and 57
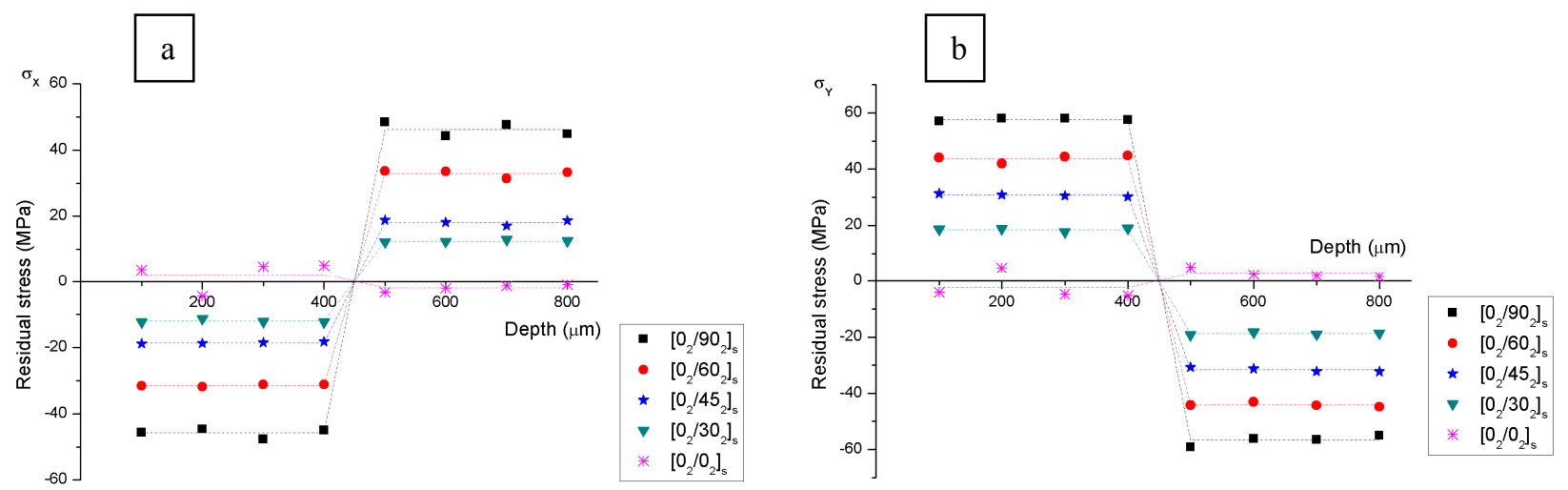

Fig. 4 Residual stress profiles versus through-thickness for laminates $\left[0_{2} / \theta_{2}\right]_{\mathrm{s}}:$ (a) $\sigma_{\mathrm{X}} ;$ (b) $\sigma_{\mathrm{Y}}$

$\mathrm{MPa}$, while for the plies $90^{\circ}$, these values change to be $47 \mathrm{MPa}$ and $-56 \mathrm{MPa}$, respectively. The results in our study are well validated comparing with the cross-ply laminate results presented by the simulation using the classical thermo viscoelastic approach [10], and by the results in the literature $[8,9]$ through experiments. The residual stresses for unidirectional laminate $[0]_{8}$ are so small $(<5$ $\mathrm{MPa})$ no matter in which ply that the result variation is almost equal to the final average. Reminding that residual stresses in composite laminated are formed due to several raisons (polymer shrinkages, mismatches of thermal coefficients between fiber and matrix, and also between the plies in different orientations), through results comparison between $\left[0_{2} / 90_{2}\right]_{\mathrm{s}}$ and $[0]_{8}$, it can be found out that the effect of ply orientation is more important than the difference between thermal expansion coefficients of fiber and matrix for the residual stresses formation in composite laminates.

As for the laminates $\left[0_{2} / \theta_{2}\right]_{\mathrm{s}}\left(\theta=30^{\circ}, 45^{\circ}, 60^{\circ}\right)$, the results are close to those of cross-ply laminates. However, the residual stress order is lower than the latter. The results indicate the fact that the larger angle difference between the plies in various orientations becomes, the higher residual stress order comes out. It should be respected that for laminates $\left[0_{2} / \theta_{2}\right]_{\mathrm{s}}$ the plies subject tensile stress in the fiber direction and compressive stress along the vertical direction.

\section{Aging effect}

Although CFRP composites and structures are increasingly being used, their durability under the hot/wet exposure is still not understood [11]. Generally, the hydrothermal condition tends to degrade the performance of polymeric materials, which decreases the service life of CFRP composite materials [12]. For our work, the attention is given to the correction between the hydrothermal conditions and the residual stresses redistribution and then the materials mechanical properties. The 
accelerated aging test with cross-ply laminates $\left[0_{2} / 90_{2}\right]_{\mathrm{S}}$ were conducted under the environment $50^{\circ} \mathrm{C}-80 \% \mathrm{RH}$ (relative humidity) for 10 days. The temperature and $\mathrm{RH}$ were kept constant during the whole process of testing. The status of all specimens was assumed to be the original stage of the whole moisture diffusion process, in considering that the specimens were placed into the experimental environment after their thermo manufacturing.

Residual stress redistribution in cross-ply laminates $\left[0_{2} / \mathbf{9 0}_{2}\right]_{\mathrm{s}}$. With the approach proposed in the first part of this work, the residual stress redistribution results for cross-ply laminates after accelerated aging are illustrated in Fig. 5. The results for 5 days and 10 days aging tests comparing with the results
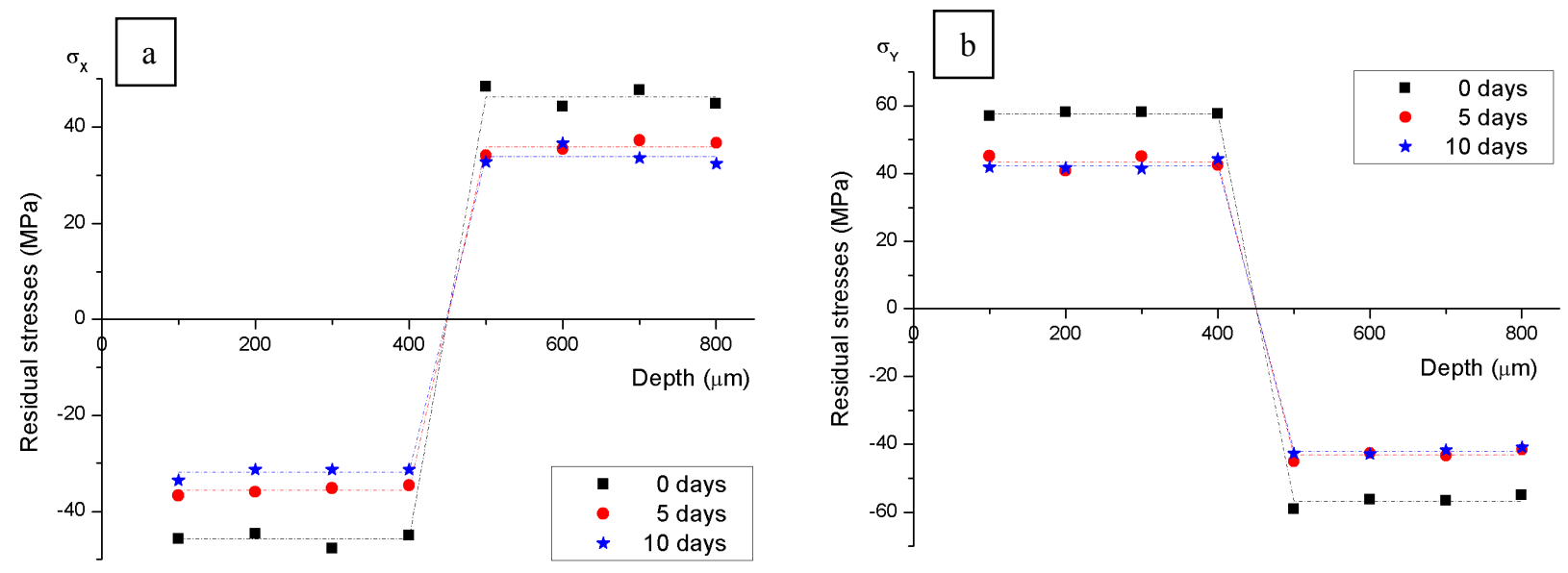

Fig. 5 Residual stress redistributions in cross-ply laminates $\left[0_{2} / 90_{2}\right]_{\mathrm{S}}$ after hydrothermal aging: (a) $\sigma_{\mathrm{X}} ;$ (b) $\sigma_{\mathrm{Y}}$ obtained in first part (regard as original state) are illustrated. It can be found that, for each aging times, the tendency of residual stress distribution appear to be similar and the principal stresses within plies in the same direction are almost uniform. The most important decrease of residual stresses occurs during the first five days, which is significantly up to $25 \%$. From the fifth day to the tenth day, it is clear that this hydrothermal aging condition has a small influence on the residual stress redistribution. Thus, the degradation of residual stresses because of hot/wet condition takes place within a relatively short period of time compared with composites service-time and the study for the aging effect on residual stresses should be concentrated on this period.
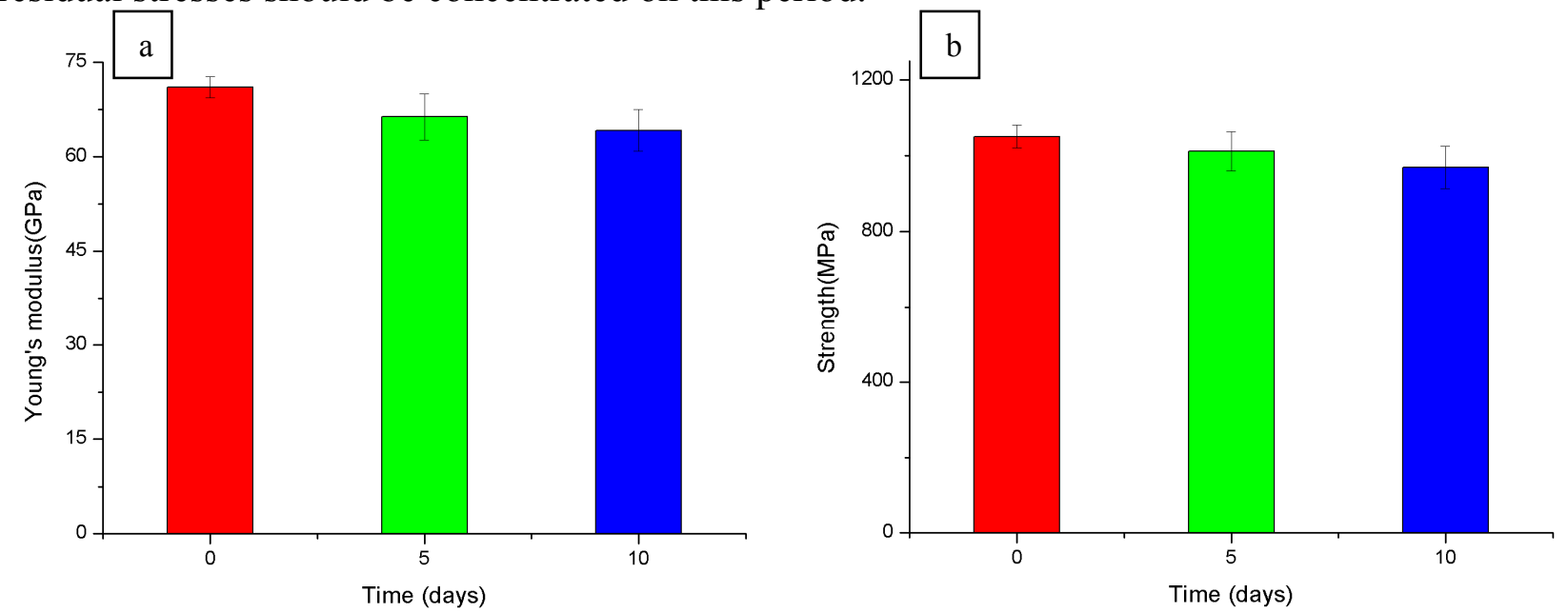

Fig. 6 Hydrothermal aging effects on the mechanical properties of cross-ply laminate $\left[0_{2} / 90_{2}\right]_{\mathrm{S}}$ : (a) Young's Modulus; (b) Strength

Hydrothermal aging effects on the mechanical properties. The initial propose of aging test concentrates on the residual stresses redistribution. However, with the objective of investigating the residual stress influence on the materials mechanical properties, it is necessary to analyze the aging effects on the mechanical properties, especially, Young's Modulus and strength of composite laminates. Obviously, each mechanical term comes down as a function of aging time. However, it should be noted that for young's modulus, the degradation rates for 5 days and 10 days are $6.6 \%$ and 
$3.2 \%$; while the results come out to be $3.8 \%$ and $4.0 \%$ for the material strength, respectively. We believe that during aging process the variations of residual stresses play an important role in the degradation of mechanical properties.

\section{Summary}

In our work, two main sections are presented. In the first part, the numerical and experimental studies are conducted to determine the residual stress distributions for composite laminates $\left[0_{2} / \theta_{2}\right]_{\mathrm{s}}$. As presented, the residual stresses profiles for various $\theta$ have the same distribution tendency with different values. In the second part, aging tests are realized to study the hydrothermal effects on the residual stress redistributions and on the mechanical properties for cross-ply laminate. The influence for residual stresses focus on the short early time ( $<5$ days) after the laminate fabrication. Then the aging effect on the material mechanical properties are simplified expressed as the reference for future study, which will be applied to study the connection between the residual stresses and the material mechanical properties.

\section{Reference}

[1] Z.K. Awad, T. Aravinthan, Y. Zhuge, F. Gonzalez. A review of optimization techniques used in the design of fibre composite structures for civil engineering applications. Materials \& Design, 33:534-544, 2012.

[2] P.P. Parlevliet, H.E.N. Bersee, A. Beukers. Residual stresses in thermoplastic composites-A study of the literature-Part I: Formation of residual stresses. Composites Part A: Applied Science and Manufacturing, 37:1847-1857, 2006.

[3] S.R. White, H.T. Hahn. Cure Cycle Optimization for the Reduction of Processing-Induced Residual Stresses in Composite Materials. Journal of Composite Materials, 27:1352-1378, 1993.

[4] J.S. Earl, R.A. Shenoi. Hygrothermal ageing effects on FRP laminate and structural foam materials. Composites Part A: Applied Science and Manufacturing, 35:1237-1247, 2004.

[5] P. Withers, H. Bhadeshia. Residual stress. Part 1-measurement techniques. Materials Science and Technology, 17:355-365, 2001.

[6] A. Niku-Lari, J. Lu, J.F. Flavenot. Measurement of residual-stress distribution by the incremental hole-drilling method. Experimental Mechanics, 25:175-185, 1985.

[7] B.R. Lake, F.J. Appl, C.W. Bert. An investigation of the hole-drilling technique for measuring planar residual stress in rectangularly orthotropic materials. Experimental Mechanics, 10:233-239, 1970.

[8] O. Sicot, X.L. Gong, A. Cherouat, J. Lu. Determination of Residual Stress in Composite Laminates Using the Incremental Hole-drilling Method. Journal of Composite Materials, 37:831-844, 2003.

[9] O. Sicot, X.L. Gong, A. Cherouat, J. Lu. Influence of experimental parameters on determination of residual stress using the incremental hole-drilling method. Composites Science and Technology, 64:171-180, 2004.

[10] O. Sicot, X.L. Gong, A. Cherouat, J. Lu, P. Olivier. New Methodology of Residual Stress Measurement in Composite Laminates: Comparison with Laminate Theory. In Proceedings of 12th $J N C, 1,471-480,2000$

[11] M. Robert, R. Roy, B. Benmokrane. Environmental effects on glass fiber reinforced polypropylene thermoplastic composite laminate for structural applications. Polymer Composites, 31:604-611, 2010.

[12] V.M. Karbhari, G. Xian. Hygrothermal effects on high VF pultruded unidirectional carbon/epoxy composites: Moisture uptake. Composites Part B: Engineering, 40:41-49, 2009. 